\title{
Smiles Arbitrary Target Specification
}

National Cancer Institute

\section{Source}

National Cancer Institute. Smiles Arbitrary Target Specification. NCI Thesaurus. Code C73484.

A language used for describing molecular patterns and properties. 